\title{
Demir eksikliği anemisi ve dispepsinin nadir bir nedeni: Duodenumda dev Brunner gland hamartomu (Brunneroma)
}

\author{
A rare cause of iron deficiency anemia and dyspepsia: A gigantic Brunner's gland hamartoma of the \\ duodenum
}

\section{Cem CENGIZ}

TOBB Ekonomi ve Teknoloji Universitesi Hastanesi, Gastroenteroloji Bölümü, Ankara

Brunner gland hamartomu duodenumdaki Brunner bezlerinden köken alan, düz kas ve yağ dokusunun da eşlik edebildiği nadir benign tümörlerdir. Küçük boyutlarda iken asemptomatiktirler. Ancak zamanla büyük boyutlara ulaşıp sıklıkla gastrik çıkış obtrüksiyonu, duodenal obstrüksiyon veya gastrointestinal hemorajiye neden olabilirler. Melena veya sadece demir eksikliği anemisi görülebilir

Anahtar kelimeler: Demir eksikliği anemisi, dispepsi, Brunner gland hamartomu

\section{GİRISS}

Brunner bezleri en fazla bulbusta olmak üzere giderek azalarak duodenum 2. ve 3. kısımlarında görülen, mukus ve bikarbonattan zengin sekresyonu ile mideden gelen asidik kimusun nötralizasyonuna yardımcı olan ve dolayısıyla intestinal sindirimi kolaylaştıran submukozal bezlerdir. Brunner bezlerinde, giderek azalan görülme sıklığına göre sırasıyla: hiperplazi, adenom ve hamartom gelişebilmektedir.

Brunner gland hamartomu çoğunlukla bulbusta, daha nadiren duodenum 2. ve 3. kısmında görülen benign polipoid lezyonlardır. Duodenal tümörlerin \%10.6'sını oluştururlar. Endoskopik olarak genellikle uzun sapl, bazen üzerinde ülserasyon izlenebilen ve büyük çaplara ulaşabilen pedinküle poliplerdir. Mikroskopik olarak hiperplazik Brunner bezleri, kanalları, düz kas, yağ dokusu ve lenfoid hücreler ile karakterizedirler. Çoğunlukla asemptomatik olmakla beraber karın ağrısı, şişkinlik, gaz, bulantı gibi dispeptik semptomlara neden olabilirler (1). En sık görülen klinik prezentasyon, gastrointestinal kanama ve intestinal obstrüksiyondur (1-9). Kanama, polibin üzerindeki ülserden kaynaklanan reküren melena ve hematemez şeklinde olabileceği gibi az miktarlarda gizli kanamaların neden olduğu demir eksikliği anemisi de görülebilir. Sapı ile birlikte on iki santimetreye kadar ulaşan boyutlarda olgular bildirilmiştir. Böyle dev boyutlara ulaştığında gastrik çıkış obstrüksiyonu (pilorik obstrüksiyon) veya duodenal obstrüksiyon ve intussusepsiyona yol
A Brunner's gland hamartoma is a rare benign tumor originating from Brunner's glands of the duodenum, also including smooth muscles and adipose tissues. It is asymptomatic when small; however, it may lead to a gastric outlet obstruction, a duodenal obstruction, or a gastrointestinal hemorrhage when it reaches a larger size over time. A melena or only an iron deficiency anemia may be seen.

Key words: Iron deficiency anemia, dyspepsia, Brunner's gland hamartoma açabilir $(5,8)$. Endoskopik tedavi ilk seçenek olmakla birlikte bazı olgularda cerrahi gerekebilir (9-15).

$\mathrm{Bu}$ yazıda, dispepsi ve demir eksikliği anemisi olan kadın hastada duodenumda görülen ve patolojik incelemede Brunner gland hamartomu tanısı alan dev pedinküle polip ve endoskopik tedavisi sunulmaktadır.

\section{OLGU SUNUMU}

Otuz sekiz yaşında kadın hasta son haftalarda tanımladığı epizodik epigastrik ağrılar nedeniyle polikliniğimize başvurdu. Özgeçmişinde peptik ülser ve 8 yll önce geçirdiği kolesistektomi kaydedildi. Fizik muayenesinde cilt ve konjonktivalarda hafif solukluk vardı; epigastrik hassasiyet ve organomegali yoktu. Laboratuvar testlerinde hemoglobin: 9.3, demir: 29, ferritin: 3.05 bulundu. Üst batın ultrason görüntülemede grade 2 steatoz dışında özellik yoktu. Takiben yapılan özofagogastroduodenoskopide duodenum 2. kısımda baş kısmı 4 $\mathrm{cm}$, kalın sapı $5 \mathrm{~cm}$, toplamda $9 \mathrm{~cm}$ uzunluğunda dev polip izlendi (Resim 1A). Biyopsi forsepsi ile çekildiğinde polibin pilordan mideye geçebildiği izlendi (Resim 1B). Polibin baş kısmının mukozası ödemli olup üzerinde 2 adet eritemli lineer erozyon dikkat çekmekte idi; kanama bulgusu yoktu. Ilk seansta polibin kalın ve uzun sapına birakılabilir kement (endoloop) konularak iskemik küçülme sağlanması planlandı. Üç gün sonra tekrarlanan endoskopide polip boyutunda 
önemli bir küçülme görülmeyerek baş ve sap kısmı ayrı ayrı snare polipektomi ile çıkartıldı. Polipektomi sonrası komplikasyon olmadı. Patolojik incelemede fibröz septalarla lobüllere ayrılan ve yer yer mukoza içine uzanan hiperplazik Brunner glandların oluşturduğu, arada bu glandlara ait duktuslar ve matür adipositler içeren polipoid gelişim izlendi. Ayrıca, polip yüzeyinin pilorik tipte glandlar içeren, mikst tipte iltihap ve ödem gösteren mide mukozası ile örtülü olduğu ve fokal ülserasyon gösterdiği izlendi. Bu mikroskopik bulgularla polipoid hamartoma (Brunneroma) ve heterotopik gastrik mukoza tanısı konuldu (Resim 2). Lezyonun submukozal olması nedeniyle yapılan 3 hafta sonraki kontrol endoskopide duodenumda kalan artık doku snare polipektomi ile alındı. Demir eksikliği anemisi için verilen oral demir tedavisinden 6 ay ve 1 yll sonra yapilan kontrollerde aneminin tekrar etmediği görüldü.

\section{TARTIŞMA}

Sunulan olguda epigastrik ağrı ve yeni tanı alan demir eksikliği anemisinin etyolojisi olarak duodenum 2. kisımda izlenen, üzerinde 2 adet lineer erozyon olan, kalın ve uzun saplı dev polibin patolojik incelemesi sonucu Brunner gland hamartomu tespit edildi. Duodenumda Brunner gland hiperplazisi ve adenomu nispeten sık görülebilmesine rağmen özellikle dev Brunner gland hamartomu nadir görülen bir lezyon olup halen literatürde 137 olgu bulunmaktadır. Benign tümörler olmakla beraber bazı olgularda obstrüktif sarılık ve papilla Vater adenokanseri ile birlikte görülmesi malign transformasyonu düşündürse de heterojenite kaybı analizlerinde bunların farklı tümörler oldukları tespit edilmiştir (7). Endoskopik olarak 1-12 cm çaplarında değişen (ortalama $4 \mathrm{~cm}$ ), pedinküle, üzeri normal duodenal mukoza ile örtülü uzun saplı polipoid lezyonlardır.

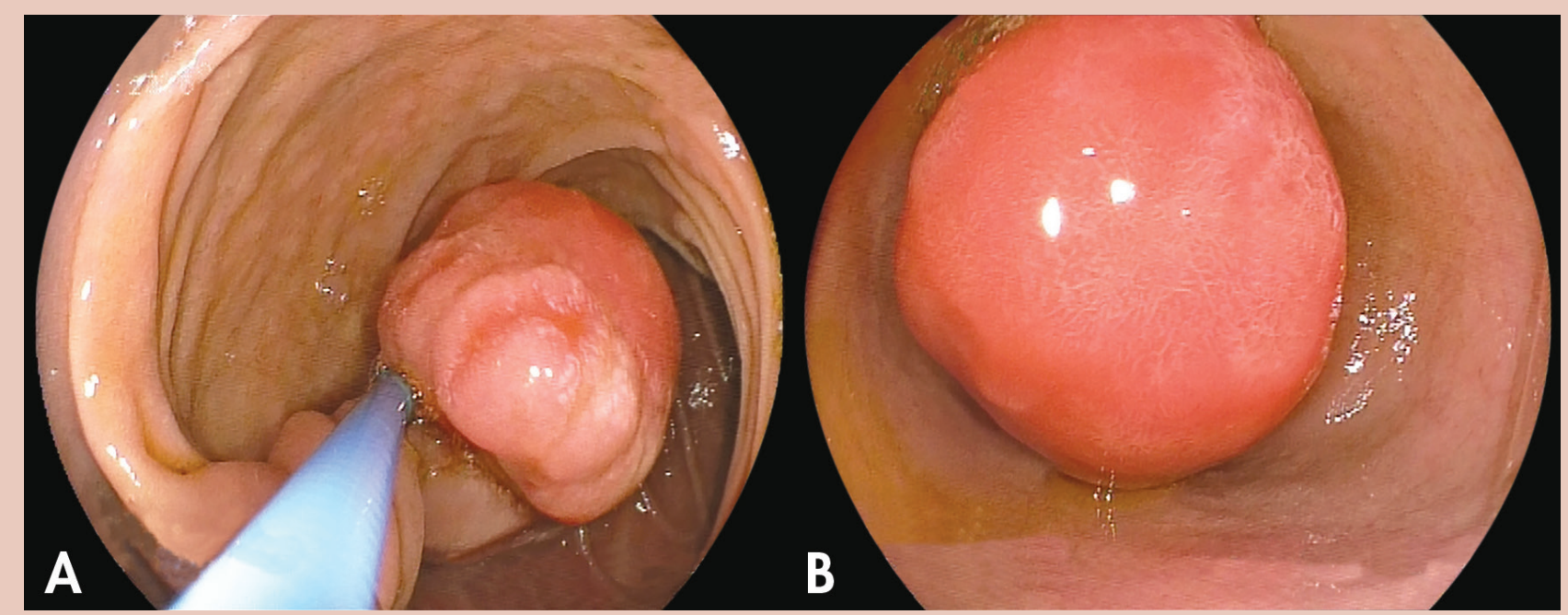

Resim 1. Duodenum 2. kısımda, normal duodenal mukoza üzerinde lineer erozyonlar izlenen kalın ve uzun saplı dev polibe bırakılabilir kement uygulaması (A). Polibin biyopsi forsepsi ile çekildiğinde pilordan mideye geçtiği görülüyor (B).

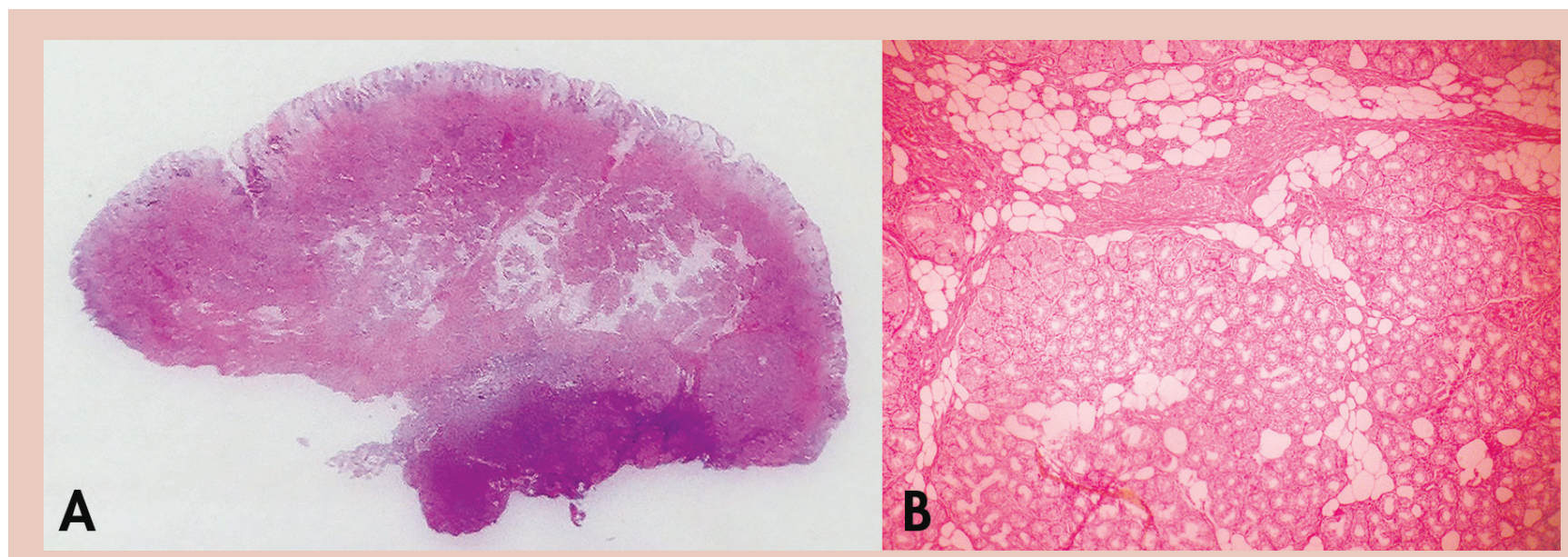

Resim 2. Polibin tam kat histolojik kesiti (A). Mikroskopide yağ dokusu ve fibromüsküler doku ile karışık olarak izlenen hiperplazik Brunner bezleri (HE, orijinal büyütme $x 40)$ (B). 
Başvuru semptom ve bulguları genellikle üst karın ağrısı, polip üzerinde gelişen ülser veya erozyonlara sekonder majör kanamalara bağlı melena ve hematemez veya minör kanamalar nedeniyle gelişen demir eksikliği anemisidir. Özellikle dev boyutlara ulaşan Brunner gland hamartomları gastrik çıkış obstrüksiyonu ve duodenojejunal intussusepsiyona yol açabilirler (5).

Yeni yayınlanan bir olgu sunumunda sunduğumuz olgudakine benzer şekilde duodenum 2. kısımda görülen uzun saplı Brunner gland hamartomunun endoskopik ultrasonografi görüntülemesinde polibin baş kısmında kistik yapılar izlenmiş olup patolojik incelemede bunların dilate Brunner gland kanalları olduğu tespit edilmiştir (12). Bir başka çalışmada da Brunner gland hamartomlarının endoskopik ultrasonografik incelemesinde karakteristik olarak tekil veya çoğul submukozal kistik lezyonlar ve heterojen solid kitleler izlenmiştir (15).

\section{KAYNAKLAR}

1. Levine JA, Burgart LJ, Batts KP, Wang KK. Brunner's gland hamartomas: clinical presentation and pathological features of 27 cases. Am J Gastroenterol 1995;90:290-4.

2. Zangara J, Kushner H, Drachenberg C, et al. Iron deficiency anemia due to a Brunner's gland hamartoma. J Clin Gastroenterol 1998;27:353-6.

3. Shemesh E, Ben Heroin S, Barshack I, Bar-Meir S. Brunner's gland hamartoma presenting as a large duodenal polyp. Gastointest Endosc 2000;52:435-6

4. Stolpman DR, Hunt GC, Sheppard B, et al. Brunner's gland hamartoma: a rare cause of gastrointestinal bleeding-case report and review of the literature. Can J Gastroenterol 2002;16:309-13.

5. Bayan K, Tüzün Y, Yilmaz S, Bilici A. Pyloric giant Brunner's gland hamartoma as a cause of both duodenojejunal intussusception and obscure gastrointestinal bleeding. Turk J Gastroenterol 2009;20:52-6.

6. Reichenbach-Klinke E, Miksch T, Orner R, et al. Hamartoma of the duodenum: a rare cause of gastrointestinal bleeding. Chirurg 2010;81:11157.

7. Hol JW, Stuifbergen WN, Teepen JL, van Laarhoven CJ. Giant Brunner's hamartoma of the duodenum and obstructive jaundice. An overview of the literature and suspicion of malignancy in a case. Dig Surg 2007;24:452-5

8. Nakabori T, Shinzaki S, Yamada T, et al. Atypical duodenal ulcer and invagination caused by a large pedunculated duodenal Brunner's gland hamartoma. Gastrointest Endosc 2014;79:679-80.
Ayırıcı tanıda, pedinküle olabilmeleri nedeniyle öncelikle lipom ve gangliositik paragangliom akılda bulundurulmalıdır.

Tedavisinde, eski yıllarda cerrahi rezeksiyon yapılmakta iken günümüzde endoskopik snare polipektomi tercih edilen tedavi yöntemleridir. Genellikle kalın ve uzun saplı olmaları nedeniyle kanama komplikasyonunun önlenmesinde polipektomi öncesi bırakılabilir kement uygulaması ve gereğinde hemoklip atılması önemlidir. Ayrıca, duodenumda uzun saplı dev polibin manipülasyonu zor olması itibariyle mümkün olan durumlarda polibin pilordan mideye çekildikten sonra endoloop ve polipektomi uygulaması teknik olarak kolaylık sağlayacaktır. Bununla birlikte endoskopik olarak çıkartılamayan olgularda (13) veya gastrik çıkış obstrüksiyonu ve intussusepsiyon olgularında hala cerrahi tedavi gerekli olabilmektedir $(5,7,13,14)$.

9. De la Riva S, Carrascosa J, Munoz-Navas M, et al. Giant Brunner's gland hamartoma: diagnosis and endoscopic treatment. Gastroenterol Hepatol 2011;34:333-6.

10. Walden DT, Marcon NE. Endoscopic injection and polypectomy for bleeding Brunner's gland hamartoma: case report and expanded literature review. Gastrointest Endosc 1998;47:403-7.

11. Chen YY, Su WW, Soon MS, Yen HH. Hemoclip-assisted polypectomy of large duodenal Brunner's gland hamartoma. Dig Dis Sci 2006;51:167072 .

12. Iwamuro M, Tanaka T, Ando S, et al. Endoscopic resection of a pedunculated Brunner's gland hamartoma of the duodenum. Case Rep Gastrointest Med 2016;2016:6707235. doi: 10.1155/2016/6707235. Epub 2016 Aug 8.

13. Sedano J, Swamy R, Jain K, Gupta S. Brunner's gland hamartoma of the duodenum. Ann R Coll Surg Engl 2015;97:70-2.

14. Gupta V, Singh V, Kalra N, Vaiphei K. Pancreas sparing resection for giant hamartoma of Brunner's glands. JOP 2009;10:196-9.

15. Hizawa K, Iwai K, Esaki M, et al. Endosonografik features of Brunner's gland hamartomas which were subsequently resected endoscopically. Endoscopy 2002;34:956-8. 